\title{
Ações educativas para promoção de atividade física por meio do agente comunitário de saúde: limitações e potencialidades
}

https://doi.org/10.11606/issn.1981-4690.v35i2p363-373

\section{Resumo}

Objetivou-se investigar limitações e potencialidades existentes a partir de uma ação educativa direcionada à Agentes Comunitários de Saúde para promoção de atividade física em adolescentes. A proposta foi pautada em um curso presencial com 12 módulos, baseado no Programa Geração Movimento. Para as coletas de dados, foi utilizado o relato de experiência, grupo focal e acompanhamento da intervenção por meio do diário de campo. Foi realizada triangulação de dados do conteúdo apresentado e análise de conteúdo a partir da pré análise dos dados, a exploração do material (codificação) e o tratamento dos resultados (categorização). Foram identificadas três categorias, sendo ambiente de trabalho: referente aos achados ligados ao ambiente de trabalho e seus fatores estruturais, burocráticos e de cunho administrativo, evidenciando maior número de limitações; Saberes e formação: referente ao processo de formação dos agentes acerca de conteúdos e da experiência, que apresentaram as maiores potencialidades para as ações; E por fim, ações de educação em saúde: baseando na influência do ambiente de trabalho sobre as práticas, referente a possibilidades encontradas nas ações de educação em saúde realizadas, por meio de fatores acerca da comunidade e ações desenvolvidas na equipe. Os benefícios apresentados dizem respeito ao aprimoramento do conhecimento dos profissionais envolvidos, em relação ao aconselhamento e a oportunidade de tomadas de iniciativas na comunidade de atuação.

PalavaAs-chave: Educação em saúde; Atividade física; Limitações; Potencialidades; Agentes Comunitários de Saúde.

\section{Introdução}

Mundialmente, $81,0 \%$ dos adolescentes de 11 a 17 anos sáo insuficientemente ativos, sendo que as meninas $(84,7 \%)$ são mais inativas do que os meninos $(77,6 \%)^{1}$. Considerando todos os benefícios que a prática regular de Atividade Física (AF) pode trazer aos adolescentes ${ }^{2}$, o Sistema Único de Saúde (SUS) apresenta-se como um importante local para realizar intervenções para promoção de atividade física e consequentemente diminuir a alta prevalência de inatividade física nessa população.

Entretanto, de acordo com o estudo de BeCKer et al. ${ }^{3}$ apenas 4 intervenções que ocorreram no SUS atendiam adolescentes (13 a 17 anos) e 3 realizaram as intervenções de forma multiprofissional. Dentro do SUS, o Agente Comunitário de Saúde (ACS) é um dos membros da equipe multiprofissional e uma importante peça chave nas açóes de educação em saúde na comunidade devido a sua aproximação e frequente relação com a população, estabelecendo a ponte destes com o ambiente da saúde ${ }^{4}$. Sendo assim, somos levados a discutir e firmar sua relevância tendo em vista o trabalho com sua equipe, no planejamento e avaliação de estratégias na comunidade e na integração comunitária ${ }^{4}$. 
Em estudos realizados na cidade de São Paulo/ $\mathrm{SP}^{5}$ e Florianópolis/SC $\mathrm{S}^{6}$, a partir de ações educativas em saúde com trabalhadores, gestores de saúde e população em geral, demonstram caminhos para a promoção da AF em diferentes âmbitos, buscando aumento nos níveis de práticas de $\mathrm{AF}$ da população participante das intervençóes ${ }^{7}$.

As ações educativas fazem parte da Política Nacional de Educação Permanente em Saúde (PNEPS), implantada pelo Ministério da Saúde em 2004 por meio da portaria 198 e possui suas diretrizes de implementação publicadas na Portaria GM/MS no 1.996/2007². A Educação Permanente em Saúde (EPS) se baseia na aprendizagem

\section{Método}

\section{Desenho do estudo}

O presente estudo trata-se de um estudo de característica experimental e exploratória, de cunho qualitativo, baseado em intervenção realizada em uma cidade de médio porte no interior do estado de São Paulo.

\section{Descrição do município}

O município encontra-se na regiāo do interior de São Paulo, na microrregião de Piracicaba. Para o ano de 2019 possuía como estimativa, uma população de 206.424 habitantes, com um Índice de Desenvolvimento Humano (IDH) de 0,803, considerado alto para o estado paulista ${ }^{14}$.

\section{Amostragem}

A população alvo da intervenção do estudo foi de ACS em exercício na Estratégia de Saúde da Família no ano de 2018, vinculados à Fundação Municipal de Saúde e cadastrados como trabalhadores da saúde em sua Equipe de Saúde da Família (EqSF).

Como área de abrangência de saúde, a cidade é composta por $25 \mathrm{EqSF}$, alocadas nas 18 Unidade de Saúde da Família (USF) com abrangência de 176 ACS municipais. Vinte e cinco participantes contemplaram a amostra provenientes de 14 Equipes, com até 3 ACS da mesma equipe, compondo a amostra do estudo. significativa e na possibilidade de transformar as práticas dos profissionais de saúde em atendimentos na Atenção Básica $(A B)$ com a integração entre ensino, serviço e comunidade? .

Todavia, diversos estudos apontaram limitaçóes nas intervençóes de EPS, tais como dificuldade de articulação entre gestores, trabalhadores, controle social e Instituição de Ensino Superior ${ }^{10}$ e ordem burocrática $^{11-13}$. Portanto, o objetivo do presente estudo foi evidenciar as limitaçóes e potencialidades existentes a partir de uma ação educativa em saúde direcionada a ACS para a promoção de atividades físicas em adolescentes instruídos por uma Instituição de Ensino Superior.

\section{Intervenção}

Os encontros foram realizados no segundo semestre de 2018, no período de Julho a Setembro.

A intervenção foi pautada na metodologia proposta pelo Programa Geração Movimento. Este trata-se de um programa premiado no ano de 2016 pelo "Prêmio Mais Movimento", tendo como objetivo inicial tornar a cultura corporal, uma abordagem mais presente no dia a dia do contexto escolar, por meio de capacitação de professores através de encontros presenciais e atividades virtuais. A proposta utiliza de uma apostila guia com 8 capítulos, sendo 2 estritamente teóricos e de base para os outros 6 que tratam de atividades divididas em blocos de conteúdo, protagonistas das práticas utilizadas para a promoção e vivência da cultura corporal ${ }^{15}$.

Foram executados módulos de atividades sendo divididos em: 1 de apresentação, 2 de discussão teórica baseadas nas metodologias da proposta, 8 de modalidades teórico/práticas (2 de Jogos e Brincadeiras, 2 de Esportes, 1 de Ginástica, 1 de Lutas, 1 de Danças e 1 de Atividades de Aventura) e 1 de encerramento de conteúdo e avaliação do processo como apresentado na abaixo (FIGURA 1). Todos os módulos contaram com momentos de debates, vivências práticas e resolução de problemas, além de atividades e propostas para confecção de materiais informativos. 
FIGURA 1 - Estrutura das ações de educação em saúde desenvolvidas com Agentes Comunitários de Saúde "Cultura corporal como estratégia de promoção de hábitos ativos na adolescência”.

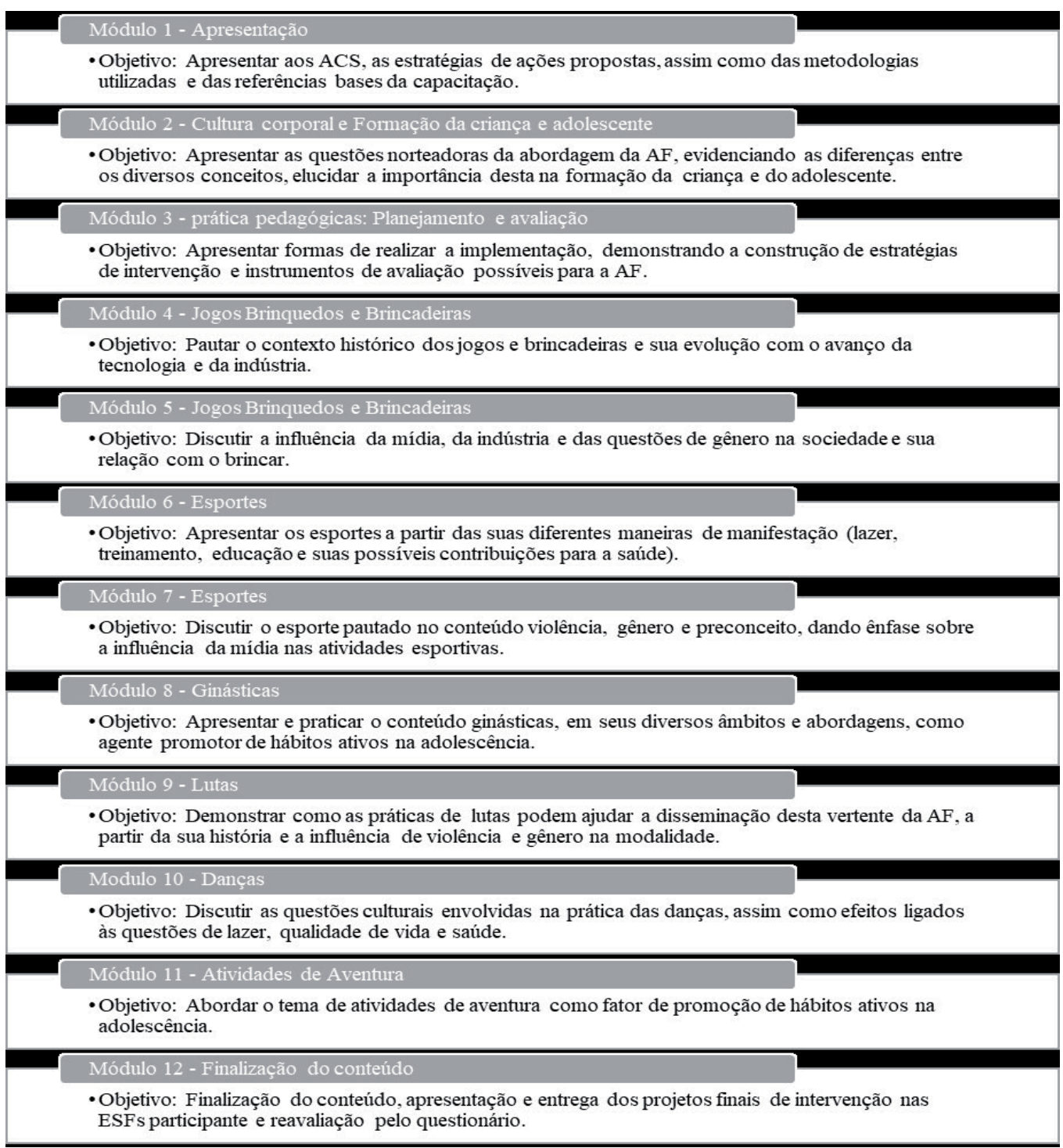

O curso contou com 12 módulos, desenvolvidos semanalmente no ambiente da universidade proponente do estudo, com duração de duas horas cada encontro. Sua realização se dava nas quartas feiras, das $14: 00$ às 16:00 horas, sendo que este dia e horário foram definidos juntamente aos participantes. O professor guia das açóes foi o pesquisador responsável do estudo (ED), acompanhado de um aluno de mestrado para auxiliar nos encontros. Como formas de acompanhamento das aulas, utilizouse estratégias de gravaçôes de áudios, filmagens, fotografias e diário de campo.

\section{Coleta de dados}

O processo de avaliação ocorreu em dois momentos, sendo o primeiro logo após a finalização dos módulos, por meio de um breve relato acerca das experiências com as açóes desenvolvidas no seu contexto de trabalho após a realização da intervenção, e a última após quatro meses da realização das açôes, por meio de grupo focal.

O grupo focal foi composto por oito questóes, evidenciando a utilização de tal técnica com objetivo de identificar as percepçóes dos ACS 
acerca das ações, buscando identificar as barreiras e facilitadores em suas práticas na difusão do conteúdo, limites e potencialidades encontradas nos caminhos durante e após o processo do curso, além de sugestôes ou críticas para melhorar as ações de educação em saúde apresentadas durante o processo.

O grupo focal foi gravado e, ao final da gravação, foi obtido um registro manuscrito de informaçóes relevantes apresentadas de acordo com as falas e uma gravação de áudio completa. A gravação de áudio foi transcrita considerando todo tipo de falsos inícios, repetições, pausas e os aspectos como sobreposição de discursos, silêncios e conversas paralelas.

A intervenção foi acompanhada com o auxílio do diário de campo, para identificação de questionamentos, apontamentos, críticas e sugestôes acerca dos temas trabalhados, nos dando o respaldo de situaçôes ocorridas durante as açốes. O uso desta metodologia se mostra como grande auxílio no processo de capacitação pessoal, enriquecendo as formaçóes de conhecimentos na proposta ${ }^{16}$.

\section{Análise de dados}

Para análise dos dados apresentados no grupo focal, relatos e informaçóes presentes no diário de campo, foi utilizado o processo de triangulação de dados, que se trata de uma estratégia usada para análise de dados qualitativos, normalmente aplicada quando existe uma variedade de técnicas para coleta de dados, utilizada no mesmo processo de investigação ${ }^{17}$. Após esse primeiro momento, a fim de analisar os conteúdos com mais profundidade, utilizou-se do método de análise de conteúdos ${ }^{18}$, propondo uma análise a partir de três fases cruciais: a pré análise, a exploração do material (codificação) e o tratamento dos resultados (categorizaçáo) ${ }^{19}$.

Este tipo de análise favoreceu a exploração de

\section{Resultados}

Participaram das açóes, 25 ACS com idade média de $38 \pm 10,79$ anos, sendo a maioria mulheres (88\%), casadas $(52 \%)$, com níveis de escolaridade entre ensino médio completo e ensino superior incompleto (54\%), com média de 32,5 $\pm 41,8$ meses de atuação na ABS e classe econômica C1 (34\%).

A intervenção chegou ao fim com $22 \mathrm{ACS}$, sendo dados com base em categorias que emergiram da conversa entre os participantes dos grupos focais e questionários, além de anotaçóes presentes no diário de campo, que buscou evidenciar a presença ou a ausência de conteúdos e características existentes nas falas, textos e expressões existentes na comunicação dos sujeitos ${ }^{20}$.

Diante os processos realizados no tratamento dos dados qualitativos, foi possível identificar separadamente as palavras chaves, totalizando 36 oriundas do grupo focal, 25 dos relatos dos questionários e 23 advindas do diário de campo. Foram encontradas palavras repetidas, o que facilitou para a criação de categorias de análise.

Frente às palavras apresentadas, ocorreu a criação de categorias de análise sendo estas:

Categoria 1 - Ambiente de trabalho: Referente aos achados diretamente ligados ao ambiente de trabalho dos ACS. Fatores estruturais, burocráticos e de cunho administrativo foram inseridos nesta categoria. Categoria 2 - Saberes e formação: Referente ao processo de formação dos ACS. Fatores acerca de conteúdos e da experiência dos participantes foram inseridos nesta categoria. E por fim, Categoria 3 - Açóes de educação em saúde: Referente a possibilidades encontradas nas açóes de educação em saúde realizadas pelos ACS. Foram inseridas nesta categoria, fatores acerca da comunidade e açóes desenvolvidas na equipe.

O estudo foi aprovado pelo comitê de ética em pesquisa com seres humanos, sob o número de parecer 3.064.018. Todos participantes assinaram o Termo de Consentimento Livre e Esclarecido (TCLE), deixando-os cientes dos processos metodológicos e de preservação de suas identidades em todos momentos da intervenção. Em caso de constrangimento, estes tiveram a liberdade de se recusarem a participar tanto da pesquisa, quanto dos momentos avaliativos.

que a perda desses ocorreu por motivos de gravidez e afastamento por período de férias trabalhistas. Para realização do grupo focal, foi requerida a presença de um representante de cada USF participante, porém, com imprevistos ocorridos no caminho, apenas nove participantes estiveram presentes nessa avaliação, sendo que os outros justificaram sua 
ausência pelo período de férias ou problemas na troca de funçóes na unidade.

\section{Categoria 1 - Ambiente de trabalho}

Esta se apresentou como a categoria que mais abrangeu as palavras presentes na pré análise, um total de 14, elencando pontos positivos acerca do ambiente de trabalho, assim como limitaçóes existentes na organização e dinamização do ambiente da USF.

Quando analisamos a fala dos ACS participantes, a pressão para cumprir as metas da equipe juntamente com a sobrecarga de trabalho dentro da USF, foram apresentados como os maiores problemas no contexto da intervenção. A fala dos participantes foram pautadas em torno da execução de tarefas dentro da unidade e a dificuldade que estes têm de se envolver em atividades que ultrapassem as de demandas administrativas e burocráticas da USF. Uma das ACS deixa muito evidente em sua fala quando expóe a dificuldade para troca de funçóes para a participação no curso ("Eu mesma tive problemas pra poder estar aqui no curso hoje. Náo querem vir fazer, e ainda náo querem dar apoio pra você fazer e crescerem juntas. Porque estou aqui pra multiplicar, né?”; GF_ACS\#3). Outra ACS, expóe que falta uma melhor atenção da coordenação geral da $\mathrm{AB}$ para com o processo de aprendizagem deles ("faltaria mais divulgação e flexibilidade também pra gente fazer.”; GF_ACS\#2).

Desta forma, somos levados a pensar novas estratégias que evidenciam a participação desta população em açóes voltadas para a formação e capacitação profissional, uma vez que tempo/ horário, foram pontos que também foram levantados em suas falas e relatos ("Então assim, a nossa realidade lá, está bem complicada, então meio que eu tenho horários específicos pra fazer os cursos e grupos (...)"; GF_ACS\#2).

As estratégias devem assim, ser pautadas nas possibilidades apresentadas dentro dos limites da $\mathrm{AB}$, uma vez que para atingir a população proposta, muitas vezes somos levados a pensar nas formas que tais ações devem ser dirigidas. Ainda nessa perspectiva, as questóes referentes a espaço/estrutura das unidades também foram apontadas como fatores limitantes para a realização de estratégias de educação em saúde, (“(...) a gente tá num impasse complicado, (...), sem o espaço da USF, a gente ainda está discutindo grupos em busca desse espaço.”; GF_ACS\#5).
Entre as tantas limitaçóes e dificuldades apontadas pelos ACS, são poucos os momentos no qual é possível evidenciar pontos positivos advindos do ambiente de trabalho, como a participação e engajamento da coordenadora de cada USF, ("A minha coordenadora abriu as portas..., a outra, ela aderiu ao projeto."; GF_ACS\#4) e o espaço para debate de formação e compartilhamento dentro das reunióes de equipe, que foram os dados mais relevantes positivamente apresentados durante as análises.

$\mathrm{Na}$ sexta feira, na reunião, cada curso que a gente faz, a $R^{*}$ e a $A^{*}$, coloca aquele agente que foi ao curso pra dividir a experiência com os outros, não tem como. O nosso foi assim, mas se o colega aceitou, aí já são outras coisas. (GF_ACS\#1)

De forma geral, quando nos referimos ao ambiente de trabalho, foi possível evidenciar mais limites que potencialidades para a realização de ações direcionadas a educação em saúde. Fatores que vão desde a burocracia envolvida na $\mathrm{AB}$ até a questão de estrutura e horários direcionados para tais atividades, são apontados como barreiras na concepção de intervençóes direcionadas à comunidade.

\section{Categoria 2 - Saberes e formação}

A segunda categoria buscou evidenciar o elementos que impactam no processo de formação do ACS, assim como os saberes que estão envolvidos nesse processo.

$\mathrm{Na}$ perspectiva inicial das ações, foi possível identificar que os profissionais participantes tinham em sua bagagem, uma visão de AF restrita ao exercício físico, em uma perspectiva pautada no processo saúde-doença, se aproximando de um olhar biomédico em torno desta relação. Quando questionados acerca de cursos e formaçôes complementares para atuação na adolescência, esse olhar pôde ser ainda mais reforçado, na qual grande parte das açóes são direcionadas a fatores referentes à gravidez, uso de drogas e doenças sexualmente transmissíveis nessa faixa etária

Já tivemos, sim, mas o que que foi? A gente trabalhar na parte de drogas, a parte da sexualidade no caso da prevenção de doenças, esse curso a gente teve sim. Mas falar do jovem, colocar ele num contexto diferente, trazer para o lado recreativo, saudável, ainda não. (GF_ACS\#1) 
Assim, quando iniciaram-se as ações, a visão de muitos ACS ainda se encontrava de maneira bem restrita, porém de acordo com o passar da intervenção, essas mudanças foram ficando mais evidentes e o entendimento de AF foi rompendo as barreiras entendidas como exercício físico, ("A minha impressão do curso no início não era muito boa, mas conforme o decorrer, vi o quâo importante é as práticas e exercícios(...)"; RL_ACS\#18), (“Antes eu tinha preguiça, e não gostava muito de fazer academia. Depois que comecei o curso, comecei a fazer dança, que eu gosto bem mais e ajuda do mesmo jeito né?”; GF_ACS\#6).

Somos levados a explicitar a relação que os ACS começaram a fazer com relação a outros conteúdos e práticas direcionadas a $\mathrm{AF}$ na adolescência. $\mathrm{O}$ esporte, os jogos e brincadeiras e as danças, foram os conteúdos que mais foram evidenciados durante o processo. Durante a intervenção foi possível identificar que os ACS já começaram a expandir sua visão, quando reconheciam a partir dos diferentes conceitos, o que poderia ser remetido a $\mathrm{AF}$, exercício físico, prática corporal entre outros, assim como quais as finalidades e objetivos de cada uma das propostas. Para eles, o conteúdo partia da experiência do movimentar-se enquanto forma de atividade, (“(...) - Ah, mas eu vou fazer uma atividade. "cê" gosta de dançar? Vai dançar que é uma atividade física."; GF_ACS1).

O uso dos elementos relacionados a conteúdos da cultura corporal como expansão da proposta de $\mathrm{AF}$, foi algo que auxiliou na disseminação e aceitação do conteúdo dentre os ACS participantes. A carga afetiva vinculada a algumas atividades realizadas fez com que os participantes se aproximam da proposta com impacto positivo, ("Só o fato de você conseguir resgatar aquelas brincadeiras antigas, que a gente fala antiga, né? Já é... algo incrível.”; GF_ACS\#4).

Aproximar os saberes diários dos ACS e a formação mais ampliada, partindo de conceitos e vivências do conteúdo menos medicalizado, se tornou algo necessário nas açóes de educação em saúde propostas na intervenção. Pensar propostas que partam das necessidades do meio que o ACS está inserido é algo que deve ser pensando e reelaborado frequentemente. A inserção de saberes e práticas advindas de outra área, neste caso da educação física, proporcionou aos participantes a possibilidade de se empoderar perante a prática de AF na adolescência (“(...) e a gente acabou com essa mania de achar que precisa de uma terceira pessoa para passar as coisas. Começar a pensar que a gente também tem capacidade pra isso, pra conhecimento."; GF_ACS\#3).

Ao contrário da categoria anterior, nesta já é possível identificar mais pontos positivos, levando a pensar que embora o ambiente seja um fator que coloque barreiras na prática, o conteúdo e saberes utilizados a partir da AF se apresenta como uma possibilidade viável de ser aplicada.

\section{Categoria 3 - Açóes de educaçáo em saúde}

Quando nos referimos às ações de educação em saúde, essa categoria expressou as potenciais estratégias de educação em saúde desenvolvidas pelos ACS e do curso ofertado para da promoção de AF na adolescência eles.

Embora os ACS ainda encontrem bastante barreiras no trabalho com adolescentes, foi possível identificar que muitos deles já pensam em como pode ser implementada novas estratégias de trabalho com essa população. Sendo o aconselhamento uma prática de rotina do ACS, o trabalho direcionado aos adolescentes já é algo que fica mais evidente em suas falas ("Eu já fico de uma certa maneira, em todas as casas que eu vou e tem criança ou adolescente, eu já fui falando que aconteceu uma coisa parecida (jogos e brincadeiras na USF), enfim, que ia acontecer e eu já fui passando pra frente." GF_ACS\#7).

Como uma das propostas das açóes, foi colocado que os ACS criassem um projeto de intervenção com temas apresentados durante o curso e que objetivava na promoção de hábitos ativos na adolescência, que pudesse ser implementado em sua USF. De acordo com os ACS, a dificuldade de implementação de tais projetos, se encontra com a apresentada na primeira categoria de análise, a questão do ambiente de trabalho

(...) ficou uma situação um pouco complicada, por que a gente ia fazer junto em parceria com um projeto, ia botar todo conteúdo dentro de um projeto, (...) estava tendo um problema burocrático, a questáo de tem que apresentar todo um dossiê, tem que falar quem que vai trabalhar e tudo mais, a gente não tava conseguindo a aprovaçáo. (GF_ACS\#2).

A burocracia envolta no sistema, mais uma vez foi apresentada como uma barreira na promoção de estratégias para intervenção dos ACS. Outra ACS, nos mostra que a descontinuação de 
coordenadores dentro das USF, também é um fator limitante ("E na hora que o negócio está fluindo, que a coordenadora tá indo, de repente chega a notícia que trocou o coordenador."; GF_ACS\#4) (“(...) a que entrou nova, já não é, já não tem a mesma visão, é diferente, é difícil, daí você fica amarrado, porque você sozinha, você não consegue.”; GF_ACS\#4).

Ainda que a implementação dos projetos seja uma atividade em desenvolvimento e as açóes de aconselhamento seja a mais palpável até o momento, os ACS já conseguiram evidenciar mudanças na realidade de suas comunidades. Houve mudanças de comportamento tanto a nível pessoal ("Eu emagreci 5 quilos..."; GF_ACS\#3), quanto no comportamento dos indivíduos que já passaram por algum tipo de ação,

"Tipo", e nos pais, eu também achei que mudou um pouco também a rotina, as escolhas, as pessoas

\section{Discussão}

Sendo o objetivo do estudo evidenciar as limitaçóes e potencialidades existentes a partir de uma ação educativa em saúde direcionada aos ACS para a promoção de atividades físicas em adolescentes, os principais achados do estudo nos mostram limitaçóes apresentadas na categoria 1 - Ambiente de trabalho, justificadas através da burocracia existente no ambiente de trabalho, assim como barreiras relacionadas à própria organização da AB. A categoria 2 - Saberes e formação encontramos as maiores potencialidades, levando em consideração o conteúdo que foi trabalhado no curso, assim como o oferecimento de uma formação direcionada aos ACS e pôr fim a categoria 3 - Ações de educação e saúde, nos mostrando que as limitaçóes existentes no ambiente de trabalho fazem com que os aconselhamentos ainda sejam as açóes mais utilizadas, embora o uso de projetos na comunidade fosse melhor aceito pelos participantes.

A maioria dos participantes do processo se trata de mulheres casadas, com faixa etária média de 38 anos, realidade que se aplica a estudos realizados em grande parte do território nacional ${ }^{21-23}$. Tal fato é comumente encontrado na $\mathrm{AB}$, na qual cargos superiores como médicos, normalmente são chegam e olha, você fez com ele, mas agora fica na minha cabeça buzinando. Pô, o que você fica fazendo em casa?; GF_ACS\#3)

Desta forma, ainda que as intervençôes sejam realizadas de maneira pontual, encontramos falas durante o processo que nos remetem que elas já caracterizam efeitos positivos na população adolescente, assim como sua família e o próprio ACS.

A elaboração de estratégias para a educação em saúde da comunidade deve ser feita em conjunto da equipe, uma vez que para seu êxito, todos devem trabalhar em benefício de uma mesma causa. Nesta categoria, foi observado que embora haja o engajamento da comunidade como um todo, ainda há limitações muito evidentes para ações de educação em saúde, em específico na população adolescente, para a promoção de hábitos ativos. A proposta de uma intervenção prática muitas vezes se caracteriza como um fator limitante.

ocupados por homens, enquanto cargos de nível médio e técnico são preenchidos por mulheres, podendo tal fato estar ligado ao papel da mulher no cuidado da saúde ou à liderança assumida na frequente busca de crescimento profissional e pessoal feminina ${ }^{23}$.

Frente aos achados da coleta de dados, três categorias foram encontradas depois da análise dos métodos utilizados: Ambiente de trabalho, Saberes e formação e Ações de educação em saúde. Embora tais características tenham sido evidenciadas de acordo com a realidade da comunidade e da USF atendida pelo estudo, somos levados a concordar com Sá, Velardi e Florindo ${ }^{13}$, no qual aponta que as limitaçóes e potencialidades apresentadas são comuns a várias outras regióes urbanas do Brasil, dado a aplicação de um modelo ainda engessado de educação em saúde no contexto da $\mathrm{AB}$.

Nos achados da categoria 1 - Ambiente de trabalho, foi possível identificar a maioria das limitaçóes apresentadas pelos ACS, partem da questáo burocrática existente dentro do ambiente de trabalho, até uma questão estrutural de acordo com o espaço reduzido que estes têm para realizar qualquer atividade que não seja de cunho administrativo da própria USF. Assim como encontrado no estudo 
de Pedraza e Santos ${ }^{24}$, o alto envolvimento dos ACS em questóes burocráticas dentro da USF, também se apresentou como prejuízo à implantação de atividades próprias da profissão, como açóes de educação em saúde e acompanhamento da comunidade nas orientaçôes de promoção de saúde.

Buscando relacionar tais fatos a outra limitação apontada, o tempo, somos levados à dissertação de $S^{25}$, na qual tal fato fica bastante evidente, quando questiona os trabalhadores da saúde sobre a não participação no programa educativo proposto, e a resposta se dá em maior parte em busca do cumprimento de metas na USF de atuação. Por se tratar de um trabalho fortemente associado ao cumprimento de metas e atendimentos, o processo de educação em saúde desse profissional, muitas vezes acaba por ficar em segundo plano, o que vai contra as características apresentadas na PNEPS.

A categoria 2 - Saberes e formação, nos leva a observar mais as potencialidades presentes no processo que as próprias limitaçóes. Assim como estudos realizados por CARdoso et al. ${ }^{26}$, SÁ, Velardi e Florindo ${ }^{13}$ e Godoi et al. ${ }^{27}$, o processo de açôes educação em saúde foi tomado como algo positivo para os participantes das propostas. Em sua totalidade, as estratégias usadas nestes estudos estavam pautadas na capacitaçáo profissional por meio de cursos oferecidos por instituiçóes de ensino superior, normalmente relacionados a um cunho de pesquisa.

Sem dúvida, a PNEPS promoveu avanços na área da educação na saúde, no entanto, requer esforços de articulação de parcerias institucionais entre serviço e ensino, educação e trabalho, numa perspectiva dialógica e compartilhada ${ }^{10}$. Tal processo, faz com que o ACS, quebre com uma lógica da atuação vertical advinda da hierarquia da formação, comumente ligada ao conselheiro superior da equipe, favorecendo a aproximação entre a equipe de saúde, comunidade acadêmica e os usuários do sistema.

$\mathrm{O}$ trato dos temas relacionados à $\mathrm{AF}$ foram fatores facilitadores dentro da proposta. Assim como em outras estudos, foi possível ampliar o conhecimento crítico sobre $\mathrm{AF}$ em diferentes dimensóes ${ }^{13}$, proporcionando aos ACS, a possibilidade de compreender uma abordagem mais ampla e emancipadora do contexto da AF. Tal aproximação de conteúdos se faz necessária na $A B$, uma vez que a presença de um professor de educação física neste contexto, pode evidenciar ainda mais em um trabalho em conjunto, proporcionando a construção de uma abordagem pautada em uma ação multiprofissional da EqSF.

$\mathrm{O}$ fato de se trabalhar ainda com a população adolescente foi algo que expressou as necessidades e ânsias dos ACS, em não possuírem uma base para atuação em tal população. Segundo o estudo "Atuação do agente comunitário de saúde no cuidado ao adolescente: propostas educativas.", os autores encontraram a partir de um levantamento bibliográfico em base de dados, 161 trabalhos com o descritor "agente comunitário de saúde", e depois de seleção e leitura de 45 estudos sobre a prática do $\mathrm{ACS}$ na $\mathrm{AB}$, não foi encontrado nenhum artigo sobre o trabalho do ACS junto ao adolescente, sendo que sua maioria estava relacionado ao trabalho com populaçóes especiais, idosos e organização no ambiente de trabalho. Isto evidencia uma carência de estudos acerca do tema e a necessidade de mais publicaçóes direcionadas às relaçóes entre esses dois grupos ${ }^{28}$.

Por fim, a categoria 3 - Ações de educação em saúde, expressou a possibilidade das açóes destes profissionais dentro do contexto da USF. Atualmente, assim como já retratado em estudos, o aconselhamento em saúde se apresenta como a estratégia mais reproduzida na comunidade ${ }^{13,24}$. Tal fato pode ser justificado pelas visitas domiciliares serem uma das responsabilidades do ACS, a fim de identificar situaçóes de risco, orientar as famílias e comunidade e encaminhar/comunicar à equipe os casos e situaçôes identificadas ${ }^{26}$, fazendo com que os ACS utilizem desse tempo para disseminar as açóes de educação em saúde na população.

Frente a isso, somos levados a recordar as falas dos participantes deste estudo, que embora vejam o projeto de intervenção como uma boa estratégia de implementação de AF para a população adolescente, se encontram de mãos atadas para sua realização, uma vez que a possibilidade de sua execução é barrada por parâmetros burocráticos da USF e da AB.

Como limitações encontradas em nosso estudo, a não participação da equipe multiprofissional foi algo bastante evidente, uma vez que a proposta pautada em açóes de educação em saúde horizontal, permitiria a médicos, enfermeiros, auxiliares de enfermagem e ACS aprenderem com o outro a partir do conhecimento proveniente de cada atuação. Outras limitaçóes evidenciadas durante o processo são remetidas a falta de participantes nos encontros, muitas vezes ocasionadas pelos trabalhos burocráticos na USF, assim como a baixa adesão de participantes no estudo. As desistências encontradas no decorrer do processo, ainda que 
baixas, evidenciaram a perda amostral de um grupo já reduzido, nos levando a pensar novas estratégias para educação em saúde desse público.

Pensando em uma forma de se tornar mais coesa, a identificação dos limites e das potencialidades das ações de educação em saúde indicam caminhos para novas pesquisas, pautadas na construção de estratégias para minimização dos fatores limitantes quanto para melhor aproveitamento das potencialidades observadas na educação em saúde desses profissionais.

Segundo Nogueira et al. ${ }^{29}$, o ACS é considerado um "elo entre os objetivos das políticas sociais do Estado e os objetivos próprios ao modo de vida da comunidade", o que corrobora com a visão de Nascimento e CorrêA ${ }^{30}$, de que o mesmo, tem a função de um mediador social, ou seja, tem objetivos claramente definidos e açóes que devem ser cumpridas dentro do contexto da USF. Ainda segundo os autores, os ACS trazem à tona a necessidade de incorporar novos elementos à sua prática, o que neste caso pode ser traduzido através da relação da promoção de AF na adolescência e a promoção de saúde, sendo esta a partir de desconfortos experimentados no cotidiano do trabalho de sua comunidade de atuação.

Como principais achados do estudo foram identificadas três categorias relacionadas às limitaçóes e potencialidades de açóes de educação em saúde de ACS: Categoria 1 - Ambiente de trabalho, Categoria 2 - Saberes e formação e pôr fim a categoria 3 - Açóes de educação e saúde, na qual a categoria 1 , apresenta as maiores limitaçóes, enquanto a 2 , maiores potencialidades acerca da ação desenvolvida.

A proposta de ações pautadas durante o processo, mostrou-se como estratégia que proporcionou aproximação entre setores como neste caso, a instituição de ensino superior e a fundação municipal de saúde. Os benefícios apresentados pelo curso são evidentes nos discursos e no aprimoramento do conhecimento dos profissionais envolvidos, não apenas em relação ao aconselhamento e a oportunidade de construção e tomadas de iniciativas na comunidade de atuaçáo, mas também à sua própria prática de $\mathrm{AF}$ e a inserção de projetos na comunidade. Futuramente, efeitos poderão ser analisados em sua prática cotidiana, sobre os impactos de tais açóes educativas em AF na saúde da população atendida.

\title{
Agradecimento
}

Ao Conselho Nacional de Desenvolvimento Científico e Tecnológico (CNPq), pelo financiamento do projeto a partir de concessão de bolsa de mestrado, através do processo 147764/2017-3.

\begin{abstract}
Educational actions to promote physical activity through the community health agent: limitations and potentiality

The objective was to investigate existing limitations and potentialities based on an educational action directed at Community Health Agents to promote physical activity in adolescents. The proposal was based on a classroom course with 12 modules, based on the Geração Movimento Program. For data collections, the experience report, focus group and follow-up of the intervention through the field diary were used. Data triangulation of the presented content and content analysis were performed based on the pre-analysis of the data, the exploration of the material (coding) and the treatment of the results (categorization). Three categories were identified, being the work environment: referring to the findings related to the work environment and its structural, bureaucratic and administrative factors, showing a greater number of limitations; Knowledge and training: referring to the process of training agents about content and experience, which presented the greatest potential for actions; And finally, health education actions: based on the influence of the work environment on practices, regarding the possibilities found in health education actions carried out, through factors about the community and actions developed in the team. The benefits presented are related to the improvement of the knowledge of the professionals involved, in relation to counseling and the opportunity to take initiatives in the operating community.
\end{abstract}

KeYwords: Health Education; Physical activity; Limitations; Potentialities; Community Health Agents. 


\section{Referências}

1. Guthold R, Stevens GA, Riley LM, Bull FC. Global trends in insufficient physical activity among adolescents: a pooled analysis of 298 population-based surveys with 1.6 million participants. Lancet Child Adolesc Heal. 2020;4(1):23-35.

2. Granger E, Di Nardo F, Harrison A, Patterson L, Holmes R, Verma A. A systematic review of the relationship of physical activity and health status in adolescents. Eur J Public Health. 2017;27(2):100-6.

3. Becker L, Gonçalves P, Reis R. Programas de promoção da atividade física no Sistema Único de Saúde brasileiro: revisão sistemática. Rev Bras Atividade Física Saúde. 2016;21(2):110.

4. Santos LPGS, Fracolli LA. O Agente Comunitário de Saúde: possibilidades e limites para a promoção da saúde. Rev Esc Enferm USP. 2010 Mar;44(1):76-83.

5. Grupo de Estudos e Pesquisas Epidemiológicas em Atividade Física e Saúde. Ambiente Ativo [Internet]. São Paulo; 2015 [citado 25 jun 2019]. Disponível em: http://www.each.usp.br/gepaf/?page_id=527\&lang=pt.

6. Universidade Federal de Santa Catarina. Projeto Vida Ativa Melhorando a Saúde - VAMOS [Internet]. Santa Catarina; 2016 [citado 25 mai 2019]. Disponível em: https://periodicos.ufsc.br/index.php/rbcdh/article/viewFile/25473/23199.

7. Benedetti TRB, Schwingel A, Salomão L, Gomez R, Chodzko-Zajko W. Programa "VAMOS” (Vida Ativa Melhorando a Saúde): da concepçâo aos primeiros resultados. Rev Bras Cineantropometria Desenvolv Hum. 2012;14(6):723-37.

8. Brasil. Portaria No 198/GM de13 de fevereiro de 2004. Institui a Política Nacional de Educação Permanente em Saúde como estratégia do Sistema Único de Saúde para a formação e o desenvolvimento de trabalhadores para o setor e dá outras providências. Diário Oficial da Uniāo. 2004; 284:99-119.

9. Brasil. Ministério da Saúde. Trabalho, Educação e Qualificação [Internet]. Brasília; 2013 [citado 18 jun 2019]. Disponível em: http://www.saude.gov.br/trabalho-educacao-e-qualificacao/gestao-da-educacao/qualificacao-profissional/40695politica-nacional-de-educacao-permanente-pneps.

10. Brasil. Ministério da Saúde. Política Nacional de Educação Permanente em Saúde: o que se tem produzido para o seu fortalecimento? [Internet]. 2018. Disponível em: http://portalarquivos2.saude.gov.br/images/pdf/2018/dezembro/13/ Politica-Nacional-de-Educacao-Permanente-em-Saude.pdf.

11. Costa EF, Andrade DR, Garcia LMT, Ribeiro EHC, Santos TI, Florindo AA. Avaliação da efetividade da promoção da atividade física por agentes comunitários de saúde em visitas domiciliares. Cad Saúde Pública. 2015; 31(10): 2185-2198.

12. Santos AM, Nóbrega, IKS, Assis MMA, Jesus SR, Kochergin CN, Bispo Júnior JP, et al. Desafios à gestáo do trabalho e educação permanente em saúde para a produção do cuidado na estratégia saúde da família. Rev APS. 2015;18(1):39-49.

13. Sá TH, Velardi M, Florindo AA. Limites e potencialidades da educação dos trabalhadores de saúde da família para promoção da atividade física: uma pesquisa participativa. Rev Bras Educ Fís Esporte. 2016;30(2):417-426.

14. Instituto Brasileiro de Geografia e Estatística. IBGE Cidades [Internet]. Brasília; 2019 [citado 18 jan 2019]. Disponível em: https://cidades.ibge.gov.br/brasil/sp/rio-claro/panorama.

15. Programa Geração Movimento. Geração movimento. Rio de Janeiro: Instituto Coca Cola, organizador. 2017. p. 1-200. v. 1

16. Minayo MCS. Pesquisa social: teoria, método e criatividade. 25. ed. rev. atual. Petrópolis: Vozes, 2007. 108 p.

17. Minayo MCS, Assis SG, Souza ER. Avaliação por triangulação de métodos: abordagem de programas sociais. Rio de Janeiro: Editora FIOCRUZ; 2005. 244 p.

18. Bardin L, Análise de conteúdo. Lisboa: Edições 70, 2004. 223 p.

19. Benites LC, Nascimento JV do, Milistetd M, Farias GO. Análise de conteúdo na investigação pedagógica em educação física: estudo sobre estágio curricular supervisionado. Mov. 2015;22(1):35.

20. Caregnato RC Aquino MR. Pesquisa qualitativa: análise de discurso versus análise de conteúdo. Texto Contexto Enferm. 2006;15(4):679-684.

21. Freitas LM, Coriolano-Marinus MWDL, Lima LS de, Ruiz-Moreno L. Formação dos agentes comunitários de saúde no município de Altamira (PA), Brasil. ABCS Heal Sci. 2015;40(3).

22. Garcia ACP, Lima RCD, Galavote HS, Coelho APS, Vieira ECL, Silva RC, et al. Agente comunitário de saúde no Espírito Santo: do perfil às atividades desenvolvidas. Trab Educ Saúde. 2016;15(1):283-300.

23. Saliba N, Garbin C, Silva F, Prado R. Agente comunitário de saúde: perfil e protagonismo na consolidaçáo da atenção primária à saúde. Cad Saúde Coletiva. 2011;19(3):318-26.

24. Pedraza DF, Santos I. Perfil e atuação do agente comunitário de saúde no contexto da Estratégia Saúde da Família em dois municípios da Paraíba. Interaçóes Campo Gd. 2017;18(3):97.

25. Hérick de Sá T. Construção e avaliação de um programa educativo para a promoção de atividade física junto a Equipes 
de Saúde da Família. Curso de Nutrição em Saúde Pública, Faculdade de Saúde Pública Universidade de São Paulo; São Paulo, 2011.

26. Cardoso FA, Cordeiro VRN, Lima DB, Melo BC, Menezes RNB, Moulaz ALS et al. Capacitação de agentes comunitários de saúde: experiência de ensino e prática com alunos de Enfermagem. Rev Bras Enferm. 2011;64(5):968-973.

27. Godoi BB, Alfradique BM, Domingos GP, Brugiolo IF, Louise V, Pessoa S, et al. Capacitação de Agentes Comunitárias de Saúde no Município de Diamantina. Rev Ciência Extensão. 2018;14(1):54-69.

28. Maia Brasil EG, Amorim DU, Queiroz MVO. Atuação do agente comunitário de saúde no cuidado ao adolescente: Propostas educativas. Adolesc Saude. 2013;10(3):28-35.

29. Nogueira RP, Silva FB, Ramos ZDVO. A vinculação institucional de um trabalhador "sui generis": o agente comunitário de saúde. IPEA Texto para discussão. 2000;(735).

30. Nascimento EPL, Correa CRS. O agente comunitário de saúde: formação, inserção e práticas. Cad Saúde Pública. 2008; 24(6):1304-1313.

\begin{tabular}{r|l} 
ENDEREÇO & \\
Erik Vinicius de Orlando Dopp & Submetido: 29/06/2020 \\
Av. 24 A, 1515 - Bela Vista & Aceito: 12/03/2021 \\
mail: erikvinicius06@gmail.com & \\
& \\
\hline
\end{tabular}

